\title{
Compensating Defects In Heavily Nitrogen- Doped Zinc Selenide: A Photoluminescence Study
}

\author{
M. Moldovan \\ S. D. Setzler \\ T. H. Myers \\ L. E. Halliburton \\ N.C. Giles
}

Follow this and additional works at: https://researchrepository.wvu.edu/faculty_publications

\section{Digital Commons Citation}

Moldovan, M.; Setzler, S. D.; Myers, T. H.; Halliburton, L. E.; and Giles, N. C., "Compensating Defects In Heavily Nitrogen-Doped Zinc Selenide: A Photoluminescence Study" (1997). Faculty Scholarship. 492.

https://researchrepository.wvu.edu/faculty_publications/492 


\title{
Compensating defects in heavily nitrogen-doped zinc selenide: A photoluminescence study
}

\author{
M. Moldovan, S. D. Setzler, T. H. Myers, L. E. Halliburton, and N. C. Giles \\ Department of Physics, West Virginia University, Morgantown, West Virginia 26506-6315
}

(Received 9 December 1996; accepted for publication 28 January 1997)

\begin{abstract}
Photoluminescence (PL) from a heavily nitrogen-doped $\mathrm{ZnSe}$ epilayer grown by molecular beam epitaxy was studied as a function of excitation wavelength, power density, and temperature. Also, the time decay of the PL emission was measured. Detailed analysis of the PL data indicates that the deep broad emission is composed of three distinct recombination processes, two are dominant at low power and a third can be detected at higher excitation power. These three bands are labeled $\mathrm{N}_{\mathrm{I}}$, $\mathrm{N}_{\text {III }}$, and $\mathrm{N}_{\text {III }}$ with corresponding peak energies at $2.54, \sim 2.58$, and $2.65 \mathrm{eV}$. The $\mathrm{N}_{\mathrm{I}}$ band is accompanied by phonon replicas of energy $69 \pm 3 \mathrm{meV}$. The behaviors of the $\mathrm{N}_{\mathrm{I}}, \mathrm{N}_{\mathrm{II}}$, and $\mathrm{N}_{\mathrm{III}}$ bands are consistent with intracenter recombination, donor-acceptor pair recombination, and electronacceptor recombination, respectively. ㅇ 1997 American Institute of Physics.

[S0003-6951(97)01813-5]
\end{abstract}

In recent years, considerable effort has focused on developing wide-band-gap semiconductors for shortwavelength light-emitting applications. Among the II-VI semiconductors, zinc selenide is the most suitable candidate for blue and blue-green lasers and light emitting diodes; however, achieving high $p$-type conductivity continues to be a problem in this material. Nitrogen is the most promising dopant for $p$-type $\mathrm{ZnSe}$, but unwanted compensating centers ${ }^{1}$ have limited the maximum achievable carrier density to the low $10^{18} \mathrm{~cm}^{-3}$ level. Optically detected magnetic resonance $e^{2.3}$ and positron annihilation ${ }^{4}$ techniques are being used to establish the identities of these device-limiting centers. Photoluminescence (PL) experiments complement these efforts by providing information about the recombination processes involving the compensating centers.

The PL from ZnSe epilayers grown by molecular beam epitaxy (MBE) changes dramatically as the level of nitrogen doping increases. Heavy nitrogen doping (mid-10 $0^{18} \mathrm{~cm}^{-3}$ and higher) is accompanied by a relatively broad deep-level luminescence $^{5-12}$ in the region from 2.45 to $2.68 \mathrm{eV}$, while samples that are lightly nitrogen doped (below the mid$10^{17} \mathrm{~cm}^{-3}$ level) exhibit conventional donor-acceptor pair (DAP) luminescence in the $2.66-2.69 \mathrm{eV}$ region. Early explanations $s^{8-12}$ of the deep luminescence have invoked a distribution of spatially separated potential wells due to a local variation in the distribution of charged impurities, thus leading to a broad band of states. These investigators assumed the deep PL emission was solely DAP recombination involving the isolated nitrogen acceptor and a donor. We suggest in the present letter that only a portion of the deep $\mathrm{PL}$ is due to DAP recombination and that the spatially separated fluctuations in the band gap are not needed to explain the deep PL data, at least for nitrogen concentrations up to $1.5 \times 10^{19} \mathrm{~cm}^{-3}$.

We have performed a PL study of heavily doped ZnSe:N epilayers grown by MBE. The PL dependence on excitation wavelength, excitation power density, and temperature was monitored. The time decay of the PL was also measured. These data distinguish the separate recombination channels involved in the deep-level luminescence. We find that the deep PL consists of three distinct radiative recombination processes. A lower energy band. labeled $\mathrm{N}_{\mathrm{l}}$, occurs at 2.54
$\mathrm{eV}$ and is accompanied by phonon replicas of energy $69 \pm 3$ meV. A second band, $\mathrm{N}_{\text {II }}$, occurs at about $2.58 \mathrm{eV}$, and displays behavior consistent with conventional DAP recombination. A third band, $\mathrm{N}_{\text {III }}$, has a peak at $2.65 \mathrm{eV}$ and is seen under high power pulsed excitation.

Our ZnSe epilayers were grown at West Virginia University in a custom MBE system. For this PL study, attention was focused on compensated $p$-type samples heavily doped with nitrogen. These films were grown at $300^{\circ} \mathrm{C}$ on semiinsulating (100) GaAs substrates using high purity $(7 N)$ elemental $\mathrm{Zn}$ and Se from conventional MBE sources. The samples exhibit low stacking fault densities as a result of atomic hydrogen cleaning of the substrate. ${ }^{13}$ An atomic nitrogen flux from a if plasma source was used for doping. Our data were obtained from a 1.8 - $\mu \mathrm{m}$-thick film containing 1.5 $\times 10^{19} \mathrm{~cm}^{-3}$ nitrogen, as determined using secondary ion mass spectroscopy.

The PL data were obtained under a variety of excitation conditions. Initial studies were conducted using continuouswave (cw) excitation. The $325 \mathrm{~nm}$ output from a $\mathrm{HeCd}$ laser was focused onto the sample surface for above-band-gap $\mathrm{cw}$ excitation. Below-band-gap $\mathrm{cw}$ excitation (458 and 476.5 $\mathrm{nm}$ ) was provided by an argon ion laser. Incident power densities were varied from $1.4 \mathrm{~mW} / \mathrm{cm}^{2}$ to $5 \mathrm{~W} / \mathrm{cm}^{2}$ using neutral density filters. The PL signals produced by $\mathrm{cw}$ excitation were detected with a grating monochromator, a photomultiplier tube (PMT) with a GaAs (Cs) cathode, and a lock-in amplifier. Time-resolved PL studies were conducted using the $355 \mathrm{~nm}$ output from a $Q$-switched Nd:YAG laser operating at $10 \mathrm{~Hz}$ repetition rate. The average power incident on the sample was $128 \mu \mathrm{W} / \mathrm{cm}^{2}$, which corresponds to $12.8 \mu \mathrm{J} / \mathrm{cm}^{2}$ per pulse. The PL signals produced by pulse excitation were measured using the HR-640 monochromator, the GaAs PMT tube, and a digital oscilloscope. The system time-decay response, determined by monitoring the laser pulse, was about 3.5 ns. All PL spectra have been corrected for the wavelength response of the detection system.

Figure 1 shows the PL spectra obtained from the heavily nitrogen-doped $\mathrm{ZnSe}$ epilayer using 325 [curve (a)] and 458 $\mathrm{nm}$ [curve (b)] excitation at $4.8 \mathrm{~K}$, and using $458 \mathrm{~nm}$ exci- 


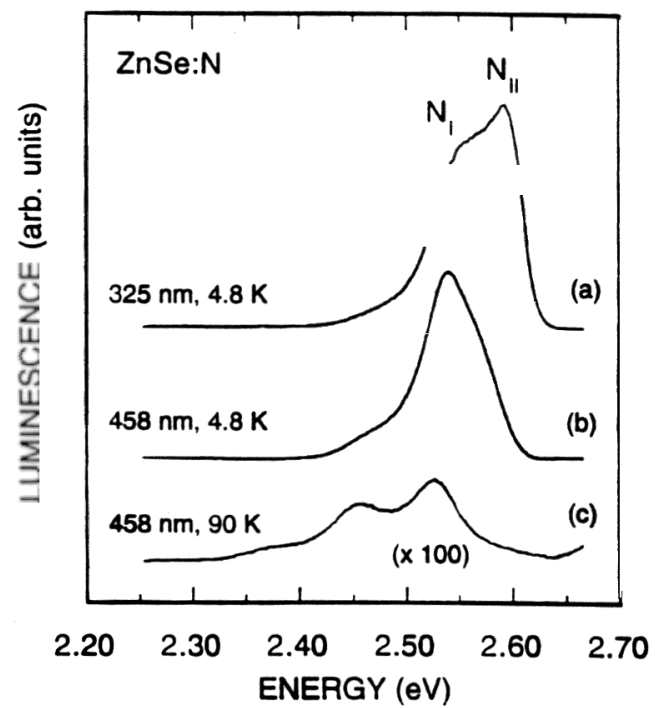

FIG. 1. The PL from a heavily nitrogen-doped $\mathrm{ZnSe}$ epilayer (a) at $4.8 \mathrm{~K}$ using $325 \mathrm{~nm}$ above-band-gap excitation. (b) at $4.8 \mathrm{~K}$ using $458 \mathrm{~nm}$ belowband-gap excitation. and (c) at $90 \mathrm{~K}$ using $458 \mathrm{~nm}$ below-band-gap excitation.

tation at $90 \mathrm{~K}$ [curve (c)]. The incident power density was 2 $\mathrm{W} / \mathrm{cm}^{2}$. The change in appearance of the luminescence for above- and below-band-gap excitation suggests that two PL bands are present. These bands are labeled $\mathrm{N}_{\mathrm{I}}$ and $\mathrm{N}_{\mathrm{II}}$. Although not shown, $N_{I}$ could still be detected using $476.5 \mathrm{~nm}$ $(2.60 \mathrm{eV})$ excitation. Phonon replicas, spaced by approximately $70 \mathrm{meV}$, are associated with $\mathrm{N}_{\mathrm{I}}$ and are easily seen at higher temperature [curve (c)]. This phonon has an energy considerably larger than the $32 \mathrm{meV}$ longitudinal optical (LO) phonon of the $\mathrm{ZnSe}$ lattice. It is possible that interference effects due to film thickness are also present in curve (c).

The power dependence of the $\mathrm{N}_{\mathrm{I}}$ and $\mathrm{N}_{\mathrm{II}}$ bands is shown in Fig. 2. These spectra were obtained using above-band-gap excitation $(325 \mathrm{~nm})$ and the incident power density was varied by more than three orders of magnitude. The spectra are displaced vertically and are enhanced by the factors shown on the plots. At the lowest power density shown, the $N_{I}$ peak occurs at about $2.54 \mathrm{eV}$. As the power density is increased, the second peak, $\mathrm{N}_{\mathrm{II}}$, emerges on the high energy side of the spectrum. At the highest power, the $\mathrm{N}_{\text {II }}$ band is dominant. The peak energy of the $\mathrm{N}_{\mathrm{I}}$ band does not appear to shift with changes in excitation power. In contrast, the $\mathrm{N}_{\text {II }}$ band shifts slightly with changes in excitation power.

To determine the peak positions and relative amplitudes of the $\mathrm{N}_{\mathrm{I}}$ and $\mathrm{N}_{\mathrm{II}}$ bands at each incident power density, we performed a least-squares, sum-of-Gaussians curve-fitting analysis of the data. As an example, the inset to Fig. 2 shows that the PL corresponding to the higher power densities can be described as the sum of three bands. The data from curve (c) are the dots in the inset, and the superposition of the three bands is the solid line. A similar power dependence study was performed using $458 \mathrm{~nm}$ excitation. Based on a curvefitting analysis of all the power dependence data, the $\mathrm{N}_{\text {I }}$ peak does not shift (within experimental error) as a function of incident power and the $\mathrm{N}_{\text {II }}$ peak does shift from about 2.55 $\mathrm{eV}$ (at low power) to nearly $2.61 \mathrm{eV}$ (at the highest cw powers used in our study). The phonon replica associated with

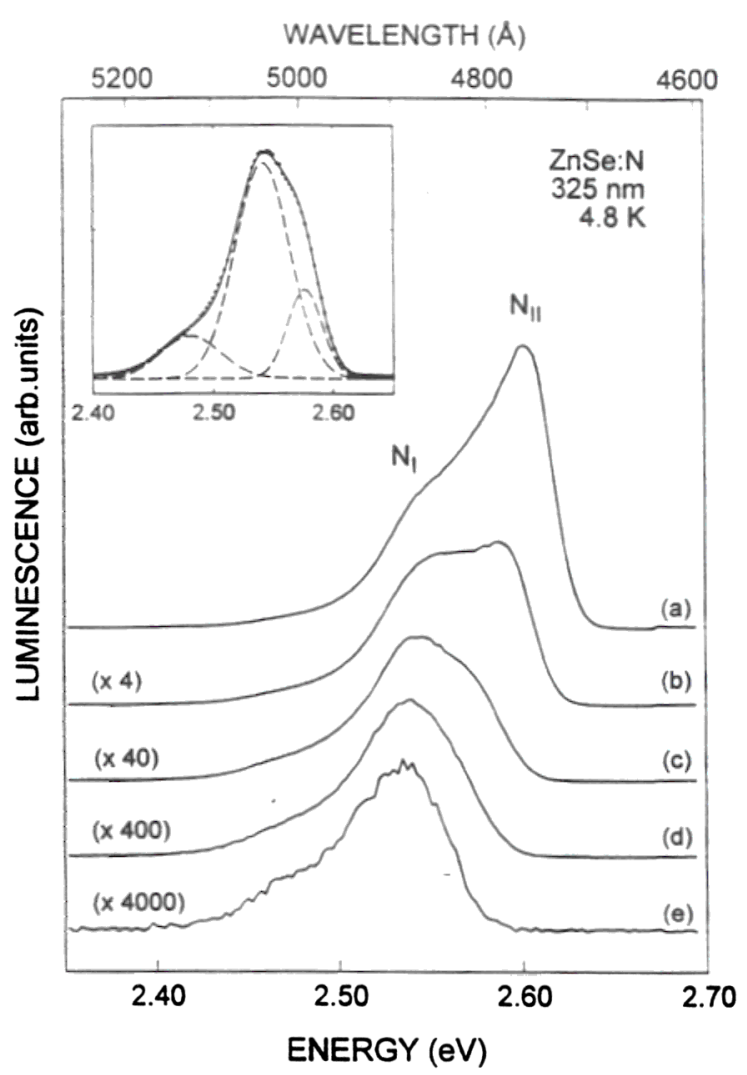

FIG. 2. The PL obtained using $325 \mathrm{~nm}$ excitation and power densities of (a) $5 \mathrm{~W} / \mathrm{cm}^{2}$, (b) $1 \mathrm{~W} / \mathrm{cm}^{2}$, (c) $0.1 \mathrm{~W} / \mathrm{cm}^{2}$, (d) $10 \mathrm{~mW} / \mathrm{cm}^{2}$, and (e) 1.40 $\mathrm{mW} / \mathrm{cm}^{2}$. The inset shows that curve (c) can be described as the sum of three bands.

$N_{\text {I }}$ was found to be $69 \pm 3 \mathrm{meV}$, in agreement with the value extracted from the $90 \mathrm{~K}$ data (see Fig. 1).

Figure 3 shows the time dependence of the PL emission from the heavily nitrogen-doped $\mathrm{ZnSe}$ epilayer. The time decay of the PL was sequentially monitored at a series of energies extending from $2.75(4500 \AA)$ to $2.40 \mathrm{eV}$ (5165 $\AA$ ) while pumping with above-band-gap $355 \mathrm{~nm}$ light. In each case, the oscilloscope was triggered independently of the PL signal (i.e., by monitoring with a second detector that portion of the laser pulse reflected from the Dewar window).

The results in Fig. 3 were obtained from the initial sets of time-decay data by extracting the PL intensity (shown as solid dots) at seven selected times, extending from 0 to $5 \mu \mathrm{s}$ after the laser pulse. The intensities are plotted on a linear scale, and the curves are displaced vertically and enhanced by the factors shown. The solid lines connect the discrete data points and provide a guide for the reader's eye. The top curve shows the PL obtained immediately after the laser pulse. In addition to the $\mathrm{N}_{\mathrm{I}}$ and $\mathrm{N}_{\text {II }}$ bands, the high-power pulsed excitation has produced a third emission band at 2.65 $\mathrm{eV}$ that decays quickly. This third band is labeled $\mathrm{N}_{\text {III }}$. Initially, the peak of $\mathrm{N}_{\text {II }}$ occurs at about $2.61 \mathrm{eV}$ but shifts to lower energy with increasing time. In contrast, the peak position of the $\mathrm{N}_{\mathrm{I}}$ band does not shift measurably with time. This difference in behavior for $\mathrm{N}_{\mathrm{I}}$ and $\mathrm{N}_{\mathrm{II}}$ clearly establishes the separate nature of the two recombination paths.

From the data presented in Figs. 1-3, we can draw a number of conclusions concerning the nature of the recombination processes associated with the $\mathrm{N}_{\mathrm{I}}, \mathrm{N}_{\mathrm{II}}$, and $\mathrm{N}_{\mathrm{III}}$ bands. First, the $\mathrm{N}_{\mathrm{II}}$ band displays the following characteristics that 


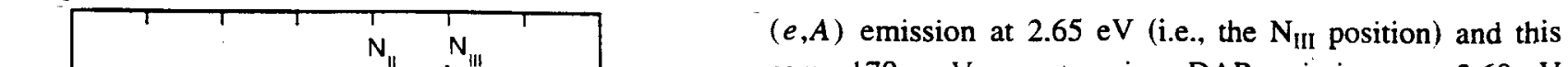

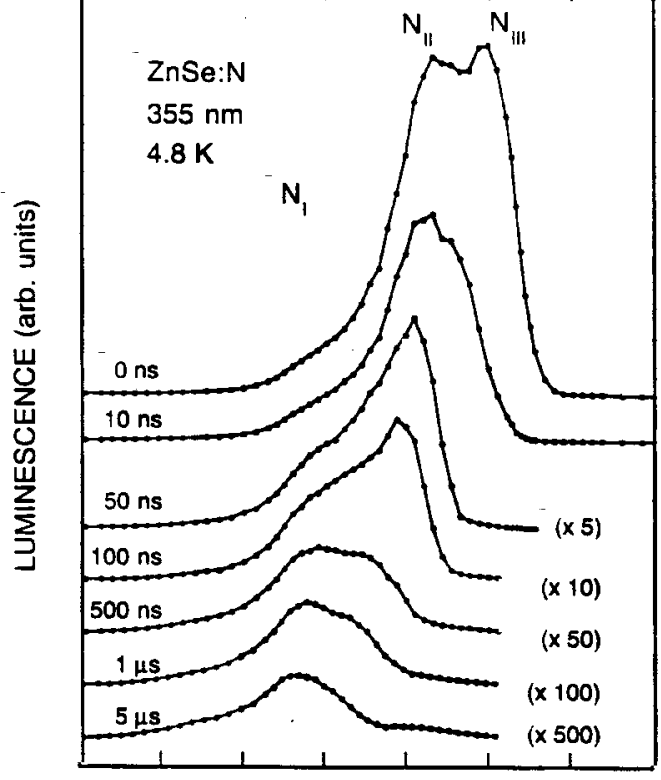

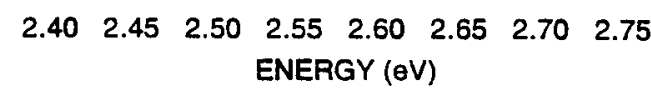

FIG. 3. Time-resolved PL spectrum from a heavily nitrogen-doped $\mathrm{ZnSe}$ epilayer. Intensities are plotted on a linear scale. Curves are displaced vertically for clarity. Several of the curves were enhanced by the factors shown.

are consistent with DAP recombination: (i) peak shift to higher energies with increasing excitation power and (ii) peak shift to lower energies with increasing time after pulsed excitation. Next, the $\mathrm{N}_{\text {III }}$ band was found to have a lifetime of $3.5 \mathrm{~ns}$ or less. This short-lifetime behavior is consistent with conduction band to valence band recombination, excitonic recombination, or band to impurity recombination. Excitonic recombination is unlikely at this high doping level. In addition to the $\mathrm{N}_{\text {III }}$ data obtained under pulsed excitation, we also observed emission at about $2.65 \mathrm{eV}$ under cw excitation when the sample temperature was above $120 \mathrm{~K}$. Finally, the $N_{l}$ band shows no shift in peak position with increasing excitation power, no shift in peak position with time, and is accompanied by phonon replicas with energy of about $69 \pm 3$ meV. The relative intensities of the $N_{I}$ phonon replicas exhibit a strong temperature dependence. Evidence for the origin of this phonon energy comes from the infrared absorption study of Stein, ${ }^{14}$ who identified a $\mathrm{Zn}-\mathrm{N}$ local vibration at $553 \mathrm{~cm}^{-1}(68.6 \mathrm{meV})$ in polycrystalline $\mathrm{ZnSe}$. This same absorption was observed ${ }^{15}$ in $\mathrm{ZnSe}: \mathrm{N}$ epilayers grown at West Virginia University. Thus, we suggest that the $N_{1}$ band at $2.54 \mathrm{eV}$ is an intracenter recombination involving a localized excitation coupled with a $\mathrm{Zn}-\mathrm{N}$ local mode.

Although the present study does not provide definitive identifications of the defects involved in the PL from heavily nitrogen doped $\mathrm{ZnSe}$, we can interpret our $\mathrm{N}_{\text {II }}$ and $\mathrm{N}_{\text {III }}$ data in terms of defect energies that have been identified by earlier investigators. A likely possibility for the origin of $\mathrm{N}_{\mathrm{III}}$ is electron-acceptor $(e, A)$ recombination since this band occurs approximately $50 \mathrm{meV}$ above $\mathrm{N}_{\mathrm{II}}$, which is DAP recombination. This $50 \mathrm{meV}$ energy agrees closely with the range of values (44-57 meV) previously associated with a deep donor in $\mathrm{ZnSe}: \mathrm{N} .^{16-19}$ If the band gap of $\mathrm{ZnSe}$ is taken to be $2.82 \mathrm{eV}$, then a $170 \mathrm{meV}$ acceptor gives electron-acceptor same $170 \mathrm{meV}$ acceptor gives DAP emission near $2.60 \mathrm{eV}$ (i.e., the $\mathrm{N}_{\mathrm{II}}$ position) when the deep donor energy of roughly $50 \mathrm{meV}$ is assumed. The energy levels being discussed here may vary by 5-10 meV depending on the strength of the pair term in DAP recombination and the uncertainty in the deep donor value. It is interesting to note that a $170 \mathrm{meV}$ acceptor in $\mathrm{ZnSe}: \mathrm{N}$ has aiready been suggested by $\mathrm{Zhu}$ et al. ${ }^{20}$

The identity of the defect responsible for the $\mathrm{N}_{\mathrm{I}}$ band is not known at this time. Hauksson et al. ${ }^{16}$ have suggested that the $\left(V_{\mathrm{Se}}-\mathrm{Zn}-\mathrm{N}_{\mathrm{Se}}\right)^{+}$complex could be the $50 \mathrm{meV}$ deep donor in $\mathrm{ZnSe:N}$. It is possible that the neutral charge state of this complex, perhaps $\left(\mathrm{V}_{\mathrm{Se}}^{+}-\mathrm{Zn}-\mathrm{N}_{\mathrm{Se}}{ }^{-}\right)^{0}$, might be the defect responsible for the intracenter recombination. We have observed an EPR signal near $g=2$ in our sample, which suggests that singly ionized selenium vacancies are present.

In conclusion, we have identified three recombination paths in a heavily nitrogen-doped $\mathrm{ZnSe}$ epilayer. The PL bands can be interpreted as intracenter, DAP, and $(e, A)$ recombinations, and only three dominant defects are needed to explain our results. A single acceptor $(\sim 170 \mathrm{meV})$ and donor $(\sim 50 \mathrm{meV})$ can account for the DAP and $(e, A)$ bands. while a selenium-vacancy-associated center may be responsible for the intracenter band. Our data suggest that at these higher doping levels, the isolated $\mathrm{N}_{\mathrm{Se}}$ acceptor $(110 \mathrm{meV})$ is not dominant.

This work was supported by the NSF/WV EPSCoR program (NSF Grant No. OSR-9255224):

' K. Prior, Phys. Status Solidi B 187, 379 (1996).

2 B. N. Murdin, B. C. Cavenett. C. R. Pidgeon. J. Simpson, I. Hauksson, and K. A. Prior, Appl. Phys. Lett. 63, 2411 (1993).

${ }^{3}$ T. A. Kennedy, E. R. Glaser, B. N. Murdin. C. R. Pidgeon, K. A. Prior, and B. C. Cavenett. Appl. Phys. Lett. 65, 1112 (1994).

${ }^{4}$ K. Saarinen, T. Laine, K. Skog. J. Makinen. P. Hautojarvi, K. Rakennus, P. Uusimaa. A. Salokatve, and M. Pessa, Phys. Rev. Lett. 77, 3407 (1996).

SJ. Qiu, J. M. DePudyt, H. Cheng, and M. A. Haase, Appl. Phys. Lett. 59. 2992 (1991).

${ }^{6}$ Z. Yang, K. A. Bowers. J. Ren, Y. Lansari. J. W. Cook, Jr., and J. F. Schetzina. Appl. Phys. Lett. 61, 2671 (1992).

${ }^{7}$ T. Yao. T. Matsumoto, S. Sasaki, C. K. Chung, Z. Zhu. and F. Nishiyama, J. Cryst. Growth 138, 290 (1994).

${ }^{8}$ P. Baume. J. Gutowski, D. Wiesmann. R. Heitz. A. Hoffmann, E. Kurtz. D. Hommel. and G. Landwehr. Appl. Phys. Lett. 67, 1914 (1995).

${ }^{9}$ P. Baume, J. Gutowski, E. Kurtz. D. Hommel, and G. Landwehr, J. Cryst. Growth 159, 252 (1996).

${ }^{10} \mathrm{C}$. Kothandaraman, G. F. Neumark, and R. M. Park, Appl. Phys. Lett. 67. 3307 (1995).

It C. Kothandaraman, G. F. Neumark, and R. M. Park, J. Cryst. Growth 159, 298 (1996).

${ }^{12}$ C. Kothandaraman. I. Kuskovsky, G. F. Neumark, and R. M. Park, Appl. Phys. Lett. 69, 1523 (1996).

${ }^{13}$ Z. Yu, S. L. Buczkowski, N. C. Giles, and T. H. Myers, Appl. Phys. Lett. 69, 82 (1996).

${ }^{14}$ H. J. Stein, Appl. Phys. Lett. 64, 1520 (1994).

${ }^{15}$ Z. Yu, S. L. Buczkowski, L. S. Hirsch, and T. H. Myers, J. Appl. Phys. 80, 6425 (1996).

${ }^{16}$ I. S. Hauksson. J. Simpson, S. Y. Wang, K. A. Prior, and B. C. Cavenett, Appl. Phys. Lett. 61, 2208 (1996).

${ }^{17}$ Z. Zhu, K. Takebayashi, K. Tanaka. T. Ebisutani, J. Kawamata, and T. Yao. Appl. Phys. Lett. 64, 91 (1994).

${ }^{18}$ Z. Zhu. G. D. Brownile, P. J. Thompson, K. A. Prior, and B. C. Cavenett, Appl. Phys. Lett. 67, 3762 (1995).

${ }^{19}$ C. Morhain. E. Tournie, G. Neu, C. Ongaretto, and J. P. Faurie, Phys. Rev. B 54, 4714 (1996).

${ }^{20}$ Z. Zhu. G. D. Brownlie, G. Horsburgh, P. J. Thompson, S. Y. Wang, K. A. Prior, and B. C. Cavenett. Appl. Phys. Lett. 67, 2167 (1995); J. Cryst. Growth 159, 248 (1996). 